\title{
CONCISE PUBLICATIONS
}

\section{Biologic Effects of 1,25-Dihydroxycholecalciferol}

\author{
(a Highly Active Vitamin D \\ Metabolite) in Acutely Uremic Rats
}

\author{
Richard G. Wong, Anthony W. Norman, Chilumula R. Reddy, and \\ JACK W. COBURN \\ From the Department of Biochemistry, University of California, Riverside, at \\ Riverside, California 92502, and Departments of Medicine, Veterans \\ Administration Hospital (Wadsworth), and UCLA School of Medicine, \\ Los Angeles, California 90024
}

\begin{abstract}
A в S T R A C T The development of a vitamin D-resistant state in the course of renal failure may be responsible for reduced intestinal absorption of calcium and an impaired response of skeletal tissue. Moreover, the kidney has been shown to carry out the conversion of 25-hydroxycholecalciferol (25-OH-CC) to a highly biologically active metabolite, 1,25-dihydroxycholecalciferol (1,25-diOH-CC). In the present studies, vitamin D-deficient rats, made acutely uremic by either bilateral nephrectomy or urethral ligation, received physiological doses of cholecalciferol (vitamin $\mathrm{D}_{3}$ ) (CC), 25-OH-CC or 1,25-diOH-CC; $24 \mathrm{hr}$ later intestinal calcium transport, in vitro, and bone calcium mobilization, in vivo, were assessed. Whereas $\mathrm{CC}$ and 25-OH-CC stimulated calcium transport in sham-operated controls, they were without effect in the uremic animals. In contrast, administration of 1,25-diOH-CC stimulated calcium transport in both groups of uremic animals. Administration of 1,25-diOH-CC also stimulated calcium mobilization from bone in each group of animals. However, CC and 25-OH-CC were only effective in the sham controls and the uremic group produced by urethral ligation and had little or no effect in animals without kidneys. These results indicate that renal conversion of calciferol to a

This work was presented in part before the 5th Annual Meeting of the American Society of Nephrology, in Washington, D. C. on 23 November 1971.

Received for publication 7 December 1971 and in revised form 28 February 1972.
\end{abstract}

more biologically active form is necessary for the stimulation of intestinal calcium absorption and calcium mobilization from bone, and that $1,25-\mathrm{diOH}-\mathrm{CC}$ may bypass a possible defect in vitamin $\mathrm{D}$ metabolism in uremia. From these studies it is likely that uremia, per se, may also impair intestinal calcium transport.

\section{INTRODUCTION}

The intestinal absorption of calcium is impaired in uremic man $(1,2)$, and diminished calcium transport has been shown in vitro in everted duodenal sacs from rats with acute or chronic uremia $(3,4)$. The impaired calcium absorption, the hypocalcemia, and the osteomalacia which occur in uremia can be reversed with vitamin D but only when very large doses are employed (2). These observations have led to the postulate that there is resistance to the action of vitamin D in uremia, either because of end-organ unresponsiveness due to uremia, per se, or due to an abnormality in the metabolism of cholecalciferol (vitamin $D_{3}$ ) or its metabolites $(2,5)$.

Available evidence indicates that cholecalciferol (CC $)^{1}$ undergoes at least two metabolic conversions before the stimulation of intestinal calcium transport. First, sidechain hydroxylation occurs in the liver (6) producing 25-hydroxycholecalciferol (25-OH-CC), the probable

${ }^{1}$ Abbreviations used in this paper: $\mathrm{CC}$, cholecalciferol; 1,25-diOH-CC, 1,25-dihydroxycholecalciferol ; 25-OH-CC, 25-hydroxycholecalciferol; Jms, rate of transport. 
major form of the vitamin circulating in the blood $(7,8)$. Subsequently, 25-OH-CC is converted to a more polar compound, shown conclusively to be 1,25-dihydroxycholecalciferol (1,25-diOH-CC) (9-11). This is the predominant metabolite of $\mathrm{CC}$ found in the intestine $(7,8)$. 1,25-diOH-CC is biologically much more active and stimulates intestinal calcium transport three times more rapidly than either CC or 25-OH-CC (12). Moreover, current evidence indicates that the kidney is the major or only organ capable of converting $25-\mathrm{OH}-\mathrm{CC}$ to 1,25 diOH-CC (13-15). Thus, it is possible, that the destruction of renal mass in uremia might impair conversion of $25-\mathrm{OH}-\mathrm{CC}$ to $1,25-\mathrm{diOH}-\mathrm{CC}$ and result in the apparent resistance to the action of vitamin $\mathrm{D}$. The present study was undertaken to evaluate the effectiveness of 1,25 $\mathrm{diOH}-\mathrm{CC}$ in an animal model of acute uremia, with the kidneys absent or present, and to compare the actions of 1,25-diOH-CC with those of CC and 25-OH-CC. Accordingly, their effects on intestinal calcium transport, studied in vitro, and on calcium mobilization from bone, in vivo, were evaluated in rats made acutely uremic by bilateral nephrectomy or urethral ligation.

\section{METHODS}

Male, weanling rats (Holtzman Co., Madison, Wis.), fed a calciferol-deficient diet (16) for 5-6 wk, were employed in two entirely separate experiments designated 1 and 2 . In each, groups of rats were made acutely uremic by either bilateral nephrectomy or urethral ligation carried out under ether anesthesia. Laparotomy and exploration of the renal areas were performed in the animals with urethral ligation and in sham-operated controls. All animals were fasted during a period from $12 \mathrm{hr}$ before surgery until they were killed. Rats from each group received i.p., in $0.2 \mathrm{ml} 1,2$ propanediol, either $50 \mathrm{IU}$ cholecalciferol, 45 or $50 \mathrm{U} 25-\mathrm{OH}$ $\mathrm{CC}, 4$ or $5.5 \mathrm{U}$ of $1,25-\mathrm{diOH}-\mathrm{CC}$, or the vehicle above (no treatment). ${ }^{2}$ The compounds were given immediately after surgery, except in rats subjected to urethral ligation in experiment 2 , where the steroids were given $6 \mathrm{hr}$ after the ligation to ensure a degree of uremia similar to that of the nephrectomized animals. Cholecalciferol and 25-OH-CC were obtained from N. V. Philips-Duphar (Weesp, The Netherlands) and 1,25-diOH-CC was produced from 25-OH-CC utilizing a kidney homogenate system in vitro as described previously (14). The 1,25-diOH-CC had been extensively chromatographed and shown to have biological activity in our standard assay before its use $(7,12)$. Blood samples were obtained at the time of decapitation $24 \mathrm{hr}$ after the injections. The proximal $4-5 \mathrm{~cm}$ of duodenum was immediately excised, washed in ice-cold $0.15 \mathrm{M} \mathrm{NaCl}$ solution, and opened longitudinally. A segment of duodenal tissue was then mounted in a modified Ussing short-circuit-type appa-

${ }^{2} 1 \mathrm{IU}$ of cholecalciferol (vitamin $\mathrm{D}_{3}$ ) is equivalent to $0.025 \mu \mathrm{g}$ or 0.065 nmoles. No formal definition of units has been formulated for 25-OH-CC and 1,25-diOH-CC. For the purposes of these experiments $1.0 \mathrm{U}$ of these compounds was arbitrarily defined as $0.025 \mu \mathrm{g}$. The actual determination of units in a sample was made by measurement of its radioactivity content. The 1,25-diOH-CC employed in these experiments had a specific activity of $2970 \mathrm{dpm} / \mathrm{U}$. ratus and ${ }^{45} \mathrm{Ca}^{2+}$ transport from the mucosal to the serosal side of the tissue was measured exactly as reported elsewhere (17). The rate of transport or flux, (Jms), was determined by employing a linear regression analysis on the rate of appearance of ${ }^{45} \mathrm{Ca}^{2+}$ and was expressed in nmoles per hour per square centimeter of tissue. Urea nitrogen and total calcium were measured in individual serum samples by the method of Siest, Vigneron, Palaszewski, and Marchal (18) and by atomic absorption flame photometry, respectively. The mean values from groups receiving each treatment in each surgical group were compared with the mean from the respective untreated animals using the Student's $t$ test. Since the data showed variability from the first to the second major experiment, the probabilities $(P)$ from the individual (i) $t$ tests were compounded according to the method of Wallis (19), whereby

$$
\chi^{2}=-4.605 \sum_{i=1}^{n} \log _{10} P_{i},
$$

with $2 \mathrm{n}$ degrees of freedom, where $\mathrm{n}$ is the number of individual probabilities. This analysis permits the combining of probabilities from separate tests of significance to determine a combined probability for the pooled experiments.

\section{RESULTS}

The effects of CC, 25-OH-CC, and 1,25-diOH-CC on intestinal calcium transport, measured in vitro, and on calcium mobilization from bone, assessed by levels of serum calcium, in the acutely uremic, calciferol-deficient rats are summarized in Table I. Each of the calciferolsteroids stimulated intestinal calcium transport in the sham-operated rats. However, in rats rendered uremic either by bilateral nephrectomy or urethral ligation, little or no augmentation of calcium transport occurred after treatment with either $\mathrm{CC}$ or 25-OH-CC. In contrast, administration of 1,25-diOH-CC resulted in an increase in calcium transport in rats made uremic either by urethral ligation or bilateral nephrectomy. These data show that 1,25-diOH-CC, when given to uremic animals, can enhance intestinal calcium transport to a greater degree than can $\mathrm{CC}$ or $25-\mathrm{OH}-\mathrm{CC}$, despite administration of a dose of $1,25-\mathrm{diOH}-\mathrm{CC}$ which was approximately $\frac{1}{10}$ those of $\mathrm{CC}$ or $25-\mathrm{OH}-\mathrm{CC}$. In experiment 1 the level of uremia was less in the urethral ligation group than in the group undergoing nephrectomy and the stimulation of calcium transport by $1,25-\mathrm{diOH}-\mathrm{CC}$ was greater in the former group.

Serum calcium levels fell in both groups of acutely uremic untreated animals. In both sham-operated animals and those with urethral ligation, calcium levels in serum increased after treatment with $\mathrm{CC}, 25-\mathrm{OH}-\mathrm{CC}$, or 1,25 diOH-CC. In contrast, serum calcium increased significantly in the rats with bilateral nephrectomy only after treatment with $1,25-\mathrm{diOH}-\mathrm{CC}$. In rats receiving no dietary intake of calcium, acute changes in the level of serum calcium reflect alterations in mobilization of calcium from bone. Thus, 1,25-diOH-CC was able to pro- 


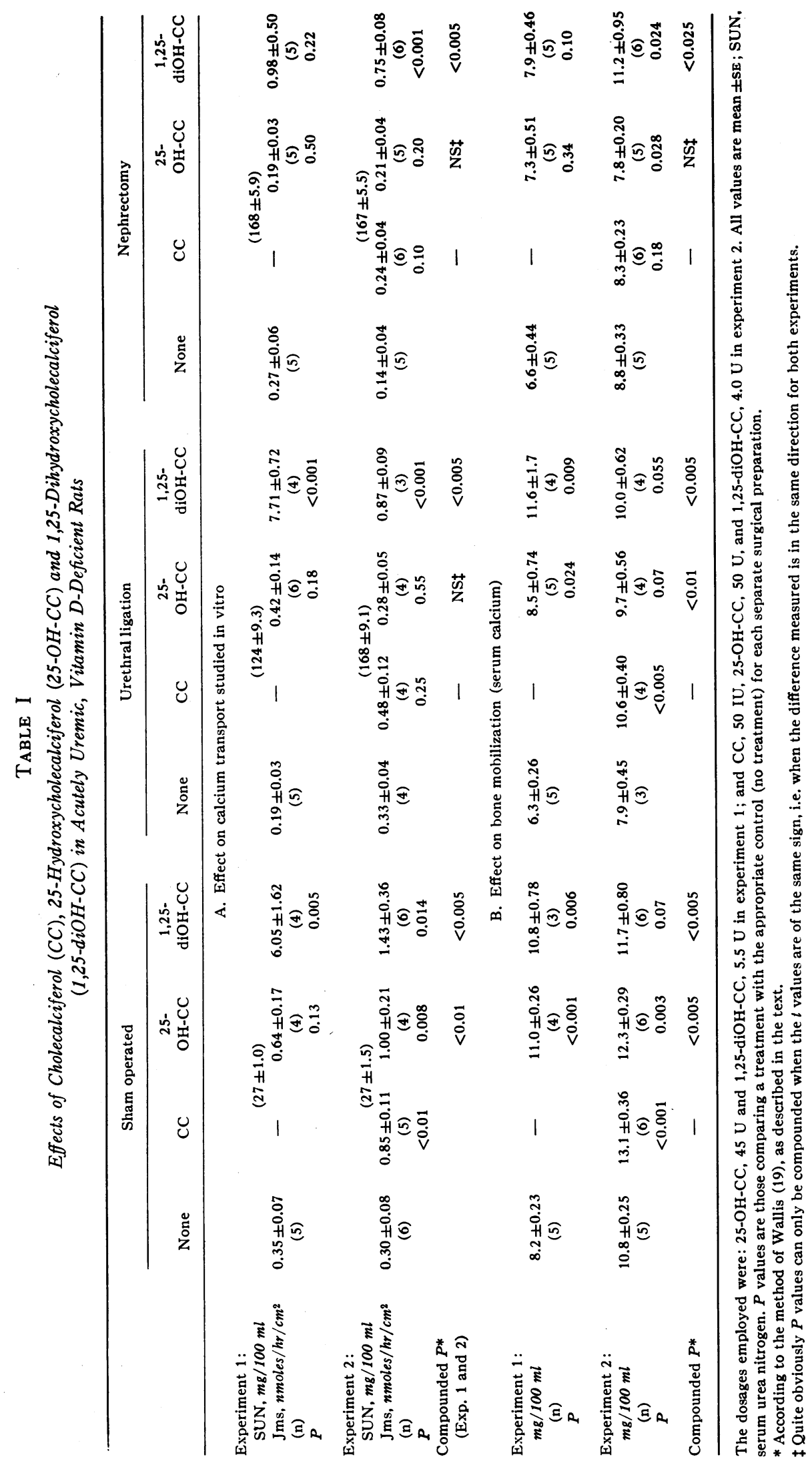


duce calcium mobilization from bone in the nephrectomized animals; $\mathrm{CC}$ and $25-\mathrm{OH}-\mathrm{CC}$ were without an effect in the nephrectomized rats but did produce an effect in uremic animals with their kidneys in place.

\section{DISCUSSION}

The results of the present study show that a very small dose of $1,25-\mathrm{diOH}-\mathrm{CC}(4-5 \mathrm{U})$ is capable of stimulating calcium transport in calciferol-deficient rats with acute uremia. The administration of $\mathrm{CC}$ and $25-\mathrm{OH}-\mathrm{CC}$, in amounts 10 times greater, produced no effect. It has been shown that radioactively labeled $\mathrm{CC}$ and $25-\mathrm{OH}-\mathrm{CC}$ are not converted to 1,25-diOH-CC after bilateral nephrectomy $(13,15)$. In contrast the conversion of these labeled compounds to $1,25-\mathrm{diOH}-\mathrm{CC}$ and the latter's presence in the intestinal mucosa are normal or near-normal in acutely uremic rats with their kidneys in situ, e.g. after ureteral ligation $(15,20)$. From such studies of the metabolic fate of CC-metabolites, it is surprising that $\mathrm{CC}$ and 25-OH-CC the precursors of 1,25-diOH-CC, failed to augment calcium transport in the uremic rats with their kidneys present. These observations suggest that uremia, per se, may adversely affect the action of CC-metabolites on the intestine. In support of this view, Hill, Van den Berg, and Mawer (20) found that 100 IU of CC (twice the dose employed in the present study) was significantly less effective in stimulating intestinal calcium transport in rats made uremic by ureteral ligation than it was in sham-operated controls. To achieve a rate of calcium transport similar to that observed in controls, which had received $100 \mathrm{IU}$ of $\mathrm{CC}, 10,000 \mathrm{IU}$ of the steroid were required in the ureterally ligated rats. Thus, the administration of very large quantities of a precursor of 1,25-diOH-CC may be able to augment calcium transport in the uremic animal. Similarly the response to only 4-5 $\mathrm{U}$ of $1,25-\mathrm{diOH}-\mathrm{CC}$ in uremia may be due to delivery and localization of a much larger quantity of the metabolite than occurs in vivo after administration of $\mathrm{CC}$ or $25-\mathrm{OH}-\mathrm{CC}^{3}$ The degree of uremia may also affect the response to 1,25-diOH-CC; thus, in experiment 1 , there was greater stimulation of calcium transport in the uremic group with lower levels of urea nitrogen, i.e. those with urethral ligation.

Although the potent action of $1,25-\mathrm{diOH}-\mathrm{CC}$ in stimulating intestinal calcium transport was clear, its action in producing calcium mobilization from bone is less clearly defined. In the present study, serum calcium levels rose in each group of animals after administration

\footnotetext{
${ }^{8}$ In the intact calciferol-deficient rat only 5-8 pmoles (0.09-0.12 U) of 1,25-diOH-CC localize in the entire intestine after $50 \mathrm{U}$ of $25-\mathrm{OH}-\mathrm{CC}$ (unpublished observations). The production of $1,25-\mathrm{diOH}-\mathrm{CC}$ is apparently closely regulated for when massive doses of $\mathrm{CC}$ are given no increased intestinal localization of $1,25-\mathrm{diOH}-\mathrm{CC}$ is observed (7).
}

of 4-5 $\mathrm{U}$ 1,25-diOH-CC, indicating that a small amount can stimulate bone mobilization. Moreover, the action of $\mathrm{CC}$ and 25-OH-CC in elevating blood calcium levels in rats with kidneys in situ and lack of such an effect after nephrectomy indicates that renal conversion of calciferol to a biologically more active form is necessary for a calcemic effect. Weber, Pons, and Kodicek (21) have recently shown that $1,25-\mathrm{diOH}-\mathrm{CC}$ is found localized in bone cell nuclei in a manner similar to that observed in intestinal mucosal nuclei $(7,8)$, suggesting that the compound responsible for the calcemic action in the urethrally ligated rat may be $1,25-\mathrm{diOH}-\mathrm{CC}$. Certainly, a small quantity of $1,25-\mathrm{diOH}-\mathrm{CC}$ can produce a calcemic effect in animals without kidneys.

The development of a vitamin D-resistant state in the course of renal failure in man may be responsible for reduced intestinal absorption of calcium and impair the responsiveness of bone to parathyroid hormone (22); both of these consequences would lead to hypocalcemia. It is thus possible that progressive kidney disease, with destruction of renal parenchyma, might result in decreased production of 1,25 -diOH-CC. The results of the present study, which show that renal conversion of calciferol is necessary before the calcium-mobilizing effect of the calciferol in bone can occur and that 1,25$\mathrm{diOH}-\mathrm{CC}$ can both stimulate intestinal calcium transport and mobilize calcium from bone in acutely uremic animals, are consistent with this thesis. However, the data suggest that uremia, per se, impairs calcium transport by the intestine, independent of the renal conversion of $\mathrm{CC}$ or 25-OH-CC to 1,25-diOH-CC. Caution should be exercised in extrapolating data obtained in calciferoldeficient, acutely uremic animals to observations in uremic man, where the renal disease is chronic and calciferol deficiency rarely exists.

\section{ACKNOWLEDGMENTS}

Mr. Ernest Tallos, Miss Patricia Roberts, and Miss June Bishop provided valuable technical assistance. Dr. Alan B. Forsythe provided aid in statistical evaluation of the data. This work was supported in part by U. S. Public Health Service grants AM-09012 and AM-14750 and contract PH43-68-1040. Dr. A. W. Norman is the recipient of a Public Health Service Career Development Award 1-K4-AM13,654 .

\section{REFERENCES}

1. Liu, S. H., and H. I. Chu. 1943. Studies of calcium and phosphorus metabolism with special reference to the pathogenesis and effect of dihydrotachysterol (A.T. 10) and iron. Medicine (Baltimore). 22: 103.

2. Stanbury, S. W., and G. A. Lumb. 1962. Metabolic studies of renal osteodystrophy I. Calcium phosphorus and nitrogen metabolism in rickets, osteomalacia and hyperparathyroidism complicating chronic uremia and the osteomalacia of the adult Fanconi syndrome. Medicine (Baltimore). 41: 1 .

1290 R. G. Wong, A. W. Norman, C. R. Reddy, and J. W. Coburn 
3. Kessner, D. M., and F. H. Epstein. 1965. Effect of renal insufficiency on gastrointestinal transport of calcium. Amer. J. Physiol. 209: 141.

4. Baerg, R. D., D. V. Kimberg, and Elaine Gershon. 1970. Effect of renal insufficiency on the active transport of calcium by the small intestine. J. Clin. Invest. 49: 1288.

5. Avioli, L. V., S. Birge, S. W. Lee, and E. Slatopolsky. 1968. The metabolic fate of vitamin $\mathrm{D}_{3}{ }^{3} \mathrm{H}$ in chronic renal failure. J. Clin. Invest. 47: 2239.

6. Ponchon, G., A. L. Kennan, and H. F. DeLuca. 1969. "Activation" of vitamin D by the liver. J. Clin. Invest. 48: 2032.

7. Myrtle, J. F., M. R. Haussler, and A. W. Norman. 1970. Evidence for the biologically active form of cholecalciferol in the intestine. J. Biol. Chem. 245: 1190.

8. Lawson, D. E. M., P. W. Wilson, and E. Kodicek. 1969. Metabolism of vitamin D: a new cholecalciferol metabolite, involving loss of hydrogen at C-1, in chick intestinal nuclei. Biochem. J. 115: 269.

9. Lawson, D. E. M., D. R. Fraser, E. Kodicek, H. R. Morris, and D. H. Williams. 1971. Identification of 1,25-dihydroxycholecalciferol, a new kidney hormone controlling calcium metabolism. Nature (London). 230: 228.

10. Holick, M. F., H. K. Schnoes, and H. F. DeLuca. 1971. Identification of 1,25-dihydroxycholecalciferol, a form of vitamin $\mathrm{D}_{3}$ metabolically active in the intestine. Proc. Nat. Acad. Sci. U. S. A. 68: 803.

11. Norman, A. W., J. F. Myrtle, R. J. Midgett, H. G. Nowicki, V. Williams, and G. Popják. 1971. 1,25-dihydroxycholecalciferol: identification of the proposed active form of vitamin $\mathrm{D}_{3}$ in the intestine. Science (Washington). 173: 51 .

12. Myrtle, J. F., and A. W. Norman. 1971. Vitamin D : a cholecalciferol metabolite highly active in promoting in- testinal calcium transport. Science (Washington). 171: 79.

13. Fraser, D. R., and E. Kodicek. 1970. Unique biosynthesis by kidney of a biologically active vitamin $\mathrm{D}$ metabolite. Nature (London). 228: 764.

14. Norman, A. W., R. J. Midgett, J. F. Myrtle, and H. G. Nowicki. 1971. Studies on calciferol metabolism I. Production of vitamin D metabolite 4B from 25-OH-cholecalciferol by kidney homogenates. Biochem. Biophys. Res. Comm. 42: 1082.

15. Gray, R., I. Boyle, and H. F. DeLuca. 1971. Vitamin D metabolism: the role of kidney tissue. Science (Washington). 172: 1232.

16. DeLuca, H. F., G. Guroff, H. Steenbock, S. Reiser, and M. Mannatt. 1961. Effect of various vitamin deficiencies on citric acid metabolism in the rat. J. Nutr. 75: 175.

17. Adams, T. H., and A. W. Norman. 1970. Studies on the mechanism of action of calciferol I. Basic parameters of vitamin D-mediated calcium transport. J. Biol. Chem. 245: 4421.

18. Siest, G., C. Vigneron, D. Palaszewski, and D. Marchal. 1968. Etude du dosage de l'uree et de la citulline en milieu proteique. Methods manvelle et automatique a la diacetlylmonoxime. Clin. Chim. Acta. 20: 373.

19. Wallis, W. A. 1942. Compounding probabilities from independent significance tests. Econometrica. 10: 229.

20. Hill, L. F., C. J. Van Den Berg, and E. B. Mawer. 1971. Vitamin D metabolism in experimental uraemia: effects on intestinal transport ${ }^{45} \mathrm{Ca}$ and on formation of 1,25dihydroxycholecalciferol in rat. Nature (London). 232: 189.

21. Weber, J. C., V. Pons, and E. Kodicek. 1971. The localization of 1,25-dihydroxycholecalciferol in bone cell nuclei of rachitic chicks. Biochem. J. 125: 147.

22. Harrison, H. E. 1966. Parathyroid hormone and vitamin D. Yale J. Biol. Med. 38: 393. 